\title{
WADAH KOMUNITAS MUSIK DI KEMBANGAN SELATAN
}

\author{
Abram Reinhold ${ }^{1)}$, Rudy Trisno ${ }^{2)}$ \\ 1) Program Studi S1 Arsitektur, Fakultas Teknik, Universitas Tarumanagara, abram_reinhold@yahoo.com \\ 2) Program Studi S1 Arsitektur, Fakultas Teknik, Universitas Tarumanagara, rudyt@ft.untar.ac.id
}

\begin{abstract}
Abstrak
Penelitian ini bertujuan untuk menulusuri tentang tempat ketiga sebagai tempat komunitas di Kelurahan Kembangan Selatan dimana merupakan lingkungan sosial yang terpisah dari dua lingkungan sosial yakni rumah dan tempat kerja. Dimana dalam penelitian ini bertujuan membahas tentang tempat ketiga komunitas musik di Kelurahan Kembangan Selatan. Permasalahan yang terjadi pada Kelurahan Kembangan Selatan adalah kondisi masyarakat saat ini melakukan berbagai rutinitas sehingga mengakibatkan kejenuhan terhadap setiap individu, pasar malam dan mall menjadi pemisah antara kalangan menengah kebawah dan menengah keatas, ketidaktersediaan tempat untuk dapat saling berinteraksi dan berkomunikasi tanpa memandang latar belakang sosial, kurangnya tempat untuk komunitas musik agar dapat melakukan interaksi dari bidang musik. Dalam mengeksekusi desain dalam proyek ini, dilakukan simbiosis, yaitu antara kekosongan dan keberadaan, sehingga mencerminkan kondisi masyarakat Kembangan Selatan dimana ada pemisah antara kalangan menengah kebawah dan menengah keatas, sehingga proyek ini memiliki makna arti kondisi masyarakat Kembangan Selatan. Karena itu Wadah Komunitas Musik ini sangat diperlukan untuk dapat berpengaruh terhadap Kelurahan Kembangan Selatan dengan tujuan memberikan emosi positif melalui musik, agar setiap masyarakat dapat saling berinteraksi dan berkomunikasi dengan baik. Kesimpulannya wadah komunitas musik ini, memberikan edukasi tentang emosi positif dari musik, sehingga dapat menyatukan berbagai lapisan masyarakat, menciptakan suasana yang menyenangkan. Menyatu dengan alam dan mencapai sustainability development goals, sehingga tercipta lingkungan yang sehat untuk mencapai kualitas hidup yang baik bagi masyarakat, dan memberikan pengaruh positif bagi pertumbuhan perekonomian kota.
\end{abstract}

Kata kunci: komunitas; musik; simbiosis; sosial; tempat ketiga

\begin{abstract}
This study aims to explore the third place as a place of community in the South Kembangan Village which is a social environment separate from the two social environments namely home and workplace. Where in this study aims to discuss about the third place of the music community in the South Kembangan Village. The problem that occurs in the South Kembangan Village is the current condition of the community to carry out various routines so that it causes saturation of each individual, the night market and malls become a separator between the lower middle and upper middle classes, the unavailability of places to be able to interact and communicate with each other regardless of social background, lack of space for the music community to be able to interact from the music field. In executing the design in this project, a symbiosis is carried out, which is between emptiness and existence, so that it reflects the condition of the South Kembangan community where there is a separation between the middle and lower classes, so that this project has a meaning of the condition of the South Kembangan community. Because of that, this Community Music Venue is very much needed to be able to influence South Kembangan Village with the aim of providing positive emotions through music, so that each community can interact and communicate well. In conclusion, this music community forum provides education about positive emotions from music, so that it can unite various layers of society, creating a pleasant atmosphere. It integrates with nature and achieves sustainability development goals, so that a healthy environment is created to achieve a good quality of life for the community, and positively influences the growth of the city's economy.
\end{abstract}

Keywords: Community; Music; Social; Symbiosis; Third Place 


\section{PENDAHULUAN}

Dalam hal ini yang menjadi pembahasan adalah kawasan Kembangan Selatan, kawasan ini memiliki keunikan yaitu terdapat pasar malam dan mall didalam kawasan Sentral Bisnis Distrik. Dimana kalangan menengah kebawah lebih cenderung pergi ke pasar malam, dan kalangan menengah keatas pergi ke mall. Sehingga hal tersebut menjadi pemisah antara kalangan menengah kebawah dan menengah keatas. Kawasan ini juga terdapat tiga sekolah musik, yaitu Yamaha Music School, Relasi Music School, KBL Permata Puri, komunitas tersebut juga tidak memiliki tempat/wadah untuk mereka dapat menyalurkan hobi mereka. Untuk itu penelitian ini perlu dilakukan, dengan desain serta motode yang telah disusun. Agar penyelesaian dalam desain dapat sesuai dengan sasaran. Sehingga third place/tempat ketiga ini, dapat menjadi penghubung antara kalangan menengah kebawah dan keatas, memberi wadah bagi komunitas musik, serta memulihkan masyarakat melalui musik sehingga mereka dapat saling berinteraksi dan berbagi emosi positif dalam kehidupan mereka untuk mencapai kualitas hidup yang baik. Third place/tempat ketiga dengan proyek ini memiliki kaitan, dimana musik digunakan sebagai media komunikasi dan third place itu sendiri memiliki aktivitas utama didalamnya, yaitu komunikasi. Tujuan dari penelitian ini yaitu, menyelesaikan isu atau permasalahan yang tejadi pada masyarakat Kembangan Selatan. Dengan memberi wadah untuk menyatukan lapisan masyarakat itu sendiri, agar mereka dapat saling berinteraksi tanpa memandang latar belakang sosial serta memberikan ruang untuk komunitas musik di Kembangan Selatan untuk mereka dapat menyalurkan hobi mereka. Wadah komunitas musik/tempat ketiga ini juga diharapkan mampu untuk memberi pertumbuhan yang baik bagi kawasan tersebut dan kota, baik itu dari segi ekonomi, perkotaan, sosial, dan lain sebagainya.

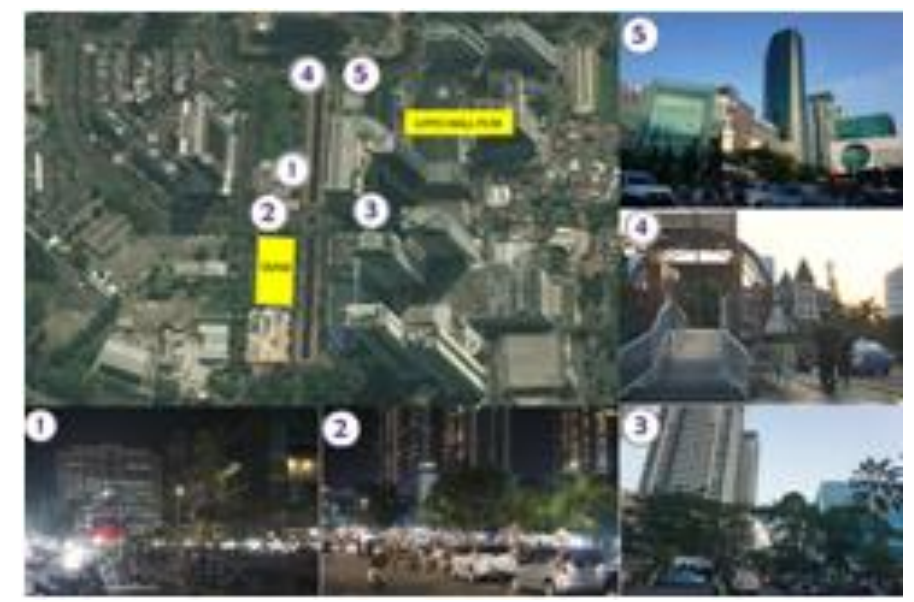

Gambar 1. Kondisi Kawasan Sekitar Tapak Sumber : Google earth dan Penulis, 2019

\section{KAJIAN LITERATUR}

\section{Open Architecture}

Aktivitas sosial dapat diartikan sebagai kegiatan yang membutuhkan kehadiran orang lain (Wei Zhang, 2009). Kegiatan ini dapat berupa perbincangan santai di pinggir jalan, bertatap muka maupun kegiatan anak-anak bermain di taman kota. Penanganan ruang publik yang kreatif dapat mendukung terbentuknya aktivitas sosial antara orang-orang yang tidak saling mengenal sebelumnya. Adanya pementasan kesenian di taman kota dapat menjadi contoh. Kegiatankegiatan kreatif yang diselenggarakan di ruang-ruang terbuka (baik yang bertujuan komersial maupun non-komersial) dapat mendorong warga untuk saling berbincang atau sekedar saling mengomentari kegiatan kreatif tersebut, demikian juga dengan pemasangan karya seni instalasi di ruang publik. Lebih lanjut, masyarakat perkotaan perlu untuk saling berbagi, baik itu dari kemampuan, pelayan, bahkan infrastruktur. Agar kota tersebut dapat menyelesaikan setiap tantangan sosial dan lingkungan. (Agyeman, 2015) 


\section{Third Place}

Oldenburg mengidentifikasi "third place" sebagai ruang publik di tempat netral, tempat orang dapat berkumpul dan berinteraksi. Berbeda dengan tempat pertama (rumah) dan tempat kedua (bekerja), tempat ketiga memungkinkan orang untuk mengesampingkan kekhawatiran mereka dan hanya menikmati perusahaan dan percakapan di sekitar mereka. Tempat ketiga "menyelenggarakan pertemuan individu, reguler, sukarela, informal, dan yang dengan gembira diantisipasi di luar ranah rumah dan pekerjaan." Oldenburg menjelaskan bahwa taman , jalanjalan utama, pub, kafe, kedai kopi, kantor pos, dan tempat ketiga lainnya adalah jantung dari vitalitas sosial komunitas. Menyediakan fondasi bagi demokrasi yang berfungsi, ruang-ruang ini mempromosikan keadilan sosial dengan meningkatkan status tamu, menyediakan latar bagi politik akar rumput, menciptakan kebiasaan asosiasi publik, dan menawarkan dukungan psikologis kepada individu dan masyarakat. (Oldenburg, 1999)

\section{Pengertian Musik}

Sejarah perkembangan musik tidak terlepas dari perkembangan budaya manusia. Karena musik merupakan salah satu hasil dari budaya manusia di samping ilmu pengetahuan, arsitektur, bahasa dan sastra, dan lain sebagainya. Menurut (Banoe, 2003), musik yang berasal dari kata muse yaitu salah satu dewa dalam mitologi Yunani kuno bagi cabang seni dan ilmu; dewa seni dan ilmu pengetahuan. Selain itu, (Sylado, 1983) juga berpendapat bahwa musik merupakan cabang seni yang membahas dan menetapkan berbagai suara ke dalam pola-pola yang dapat dimengerti dan dipahami oleh manusia. Musik merupakan wujud waktu yang hidup, yang merupakan kumpulan ilusi dan alunan suara. Alunan musik yang berisi rangkaian nada yang berjiwa akan mampu menggerakkan hati para pendengarnya. Dapat ditarik kesimpulan bahwa musik merupakan seni yang timbul dari perasaan atau pikiran manusia sebagai pengungkapan ekspresi diri, yang diolah dalam suatu nada-nada atau suara-suara yang harmonis.

\section{Teori Simbiosis}

Teori simbiosis ini diambil dari buku Kisho Kurokawa yang berjudul The Philosophy of Symbiosis. Simbiosis yakni menyatukan dua hal yang berbeda. Simbiosis dapat diartikan menyatukan elemen-elemen dari dua budaya yang berbeda dalam rancangan. Budaya yang dapat digabungkan/ disimbiosiskan beragam dan dinamis sehingga menjadi satu kesatuan yang memiliki makna yang mendalam. Menurut Kisho Kurokawa, waktu adalah sebuah evolusi dari masa lalu ke masa sekarang, dan menuju masa depan. Sehingga penyatuan kedua hal yang berbeda dapat memberi makna menghargai apa yang telah terjadi dimasa lalu dan menyesuaikan apa yang terjadi sekarang dan yang akan datang. Kisho Kurokawa dalam melakukan eksekusi terhadap bangunan Museum Art National Center di Jepang merupakan simbiosis antara tradisional Jepang dengan teknologi Modern. (Kurokawa, 1991)

\section{Teori Lingkungan}

Teori lingkungan ini diambil dari buku Otto Soemarwono yang berjudul Ekologi Lingkungan Hidup dan Pembangunan. Etika lingkungan diperlukan untuk menyeimbangkan alam dan kondisi lingkungan tersebut. Manusia merupakan bagian dari alam, manusia itu sendiri harus dapat mengelola lingkungan dan alam dimana mereka tinggal. Untuk menciptakan lingkungan yang baik manusia itu sendiri harus peka terhadap apa yang terjadi dalam lingkungan tersebut, sehingga dapat menciptakan keharmonisan dan dapat memberikan hal yang positif yang dapat dimanfaatkan dengan baik. (Soemarwono, 1994)

\section{Teori Emosi Positif}

Manusia juga membutuhkan emosi positif untuk membentuk kepribadian, agar mencapai kualitas kehidupan yang baik. (Frederickson, 2009) mengidentifikasi sepuluh emosi positif yang paling umum adalah sukacita, rasa terima kasih, ketenangan, minat, harapan, kebanggaan, 
hiburan, inspirasi, kekaguman dan cinta. Dia juga mencatat bahwa kita benar-benar membutuhkan rasio 3:1 dari positif ke negatif untuk memiliki kehidupan yang baik.

\section{Teori Bentuk Mengikuti Fungsi}

Dalam jurnal (Trisno \& Lianto, 2019) menyatakan bahwa, dalam desain arsitektur tidak ada aturan yang pasti, baik itu fungsi mengikuti bentuk, bentuk mengikuti fungsi, atau fungsi dan bentuk berjalan berdampingan. Hubungan antara konsep Fungsi dan Bentuk akan menghasilkan makna dari karya arsitektur itu sendiri.

\section{METODE}

\section{Konsep Simbiosis}

Pendekatan utama yang digunakan dari perancangan ini adalah teori simbiosis. Kisho Kurokawa mengajukan "simbiosis" sebagai dasar pemikiran postmodernismenya dalam buku The Philosophy of Symbiosis (Kurokawa, 1991). Simbiosis, merupakan prinsip mendasar dalam arsitektur. Yakni menyatukan dua hal yang berbeda. Dalam proyek ini simbiosis yang digunakan adalah antara kekosongan dan keberadaan, yang mendeskripsikan keadaan masyarakat kelurahan Kembangan Selatan dimana ada pemisah antara kalangan menengah kebawah dan menengah keatas. Dalam penerapan perancangan, simbiosis ini juga menyatukan antara kondisi fisik bangunan sekitar yaitu berbentuk persegi dengan visi yang akan dicapai oleh proyek ini. Sehingga ada pengolahan bentuk dari dua elemen yaitu persegi dan rangka, persegi itu sendiri mengartikan keberadaan, dan rangka itu mengartikan kekosongan. Oleh karena itu dengan cara demikian, akan ada arti yang mendalam pada proyek tersebut, sehingga menyatu dengan lingkungan dan dapat bermanfaat bagi kawasan kelurahan Kembangan Selatan.

\section{Bentuk Mengikuti Fungsi}

Dalam mengeksekusi bentuk desain, konsep bentuk mengikuti fungsi ini akan menjadi acuan untuk menghasilkan simbiosis dalam mempertimbangkan antara bentuk bangunan sendiri dengan bentuk bangunan lingkungan sekitar. (Trisno \& Lianto, 2019). Dari metode diatas dapat disimpulkan bahwa, konsep simbiosis dan bentuk mengikuti fungsi menjadi acuan dalam merancang bentuk bangunan. Dimana fungsi bangunan ini sebagai wadah untuk komunitas musik, maka perlu adanya harmonisasi (Sylado, 1983) antara bentuk bangunan sendiri dengan bentuk bangunan lingkungan sekitar. Sehingga hasil dari desain tersebut akan sesuai dengan sasaran serta memiliki makna bagi kawasan Kelurahan Kembangan Selatan.

\section{DISKUSI DAN HASIL}

Berdasarkan teori dan metode yang digunakan dalam mendesain bangunan serta program bangunan itu sendiri, maka perlu adanya pertimbangan serta analisis yaitu berupa; analisis lingkungan dan proses massa bangunan.

\section{Lingkungan}

Untuk menganalisis lingkungan ada dua hal yang perlu dipertimbangkan yaitu, akses pencapaian dan massa bangunan sekitar.

\section{Akses Pencapaian}

- Jalur Kendaraan

Jalur kendaraan disesuaikan dengan arah lajur kendaraan. Kemudian memperhatikan mobilitas yang terjadi sekitar tapak, sehingga tidak terjadi kemacetan pada kawasan tersebut. Akses terbaik menuju tapak untuk jalur kendaraan umum yaitu Jl. Puri Molek. Karena menghindari jalur kendaraan umum, agar mobilitas tidak tinggi. 


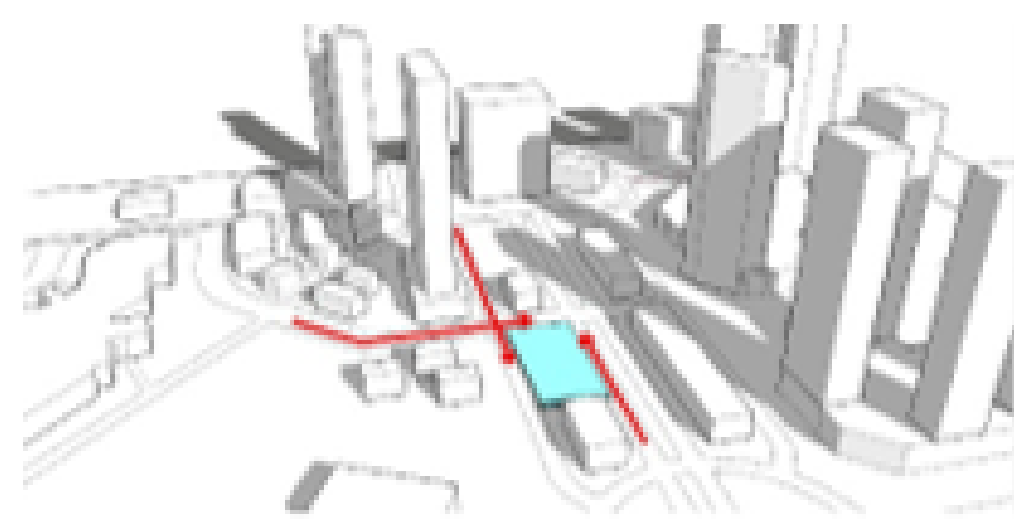

Gambar 2. Jalur Kendaraan

Sumber: Penulis, 2019

- Lokasi Halte

Jarak terdekat menuju tapak yaitu halte Puri Kembangan dan halte Puri Molek, dalam hal ini jarak halte dipertimbangkan untuk mengetahui akses dari halte menuju tapak.

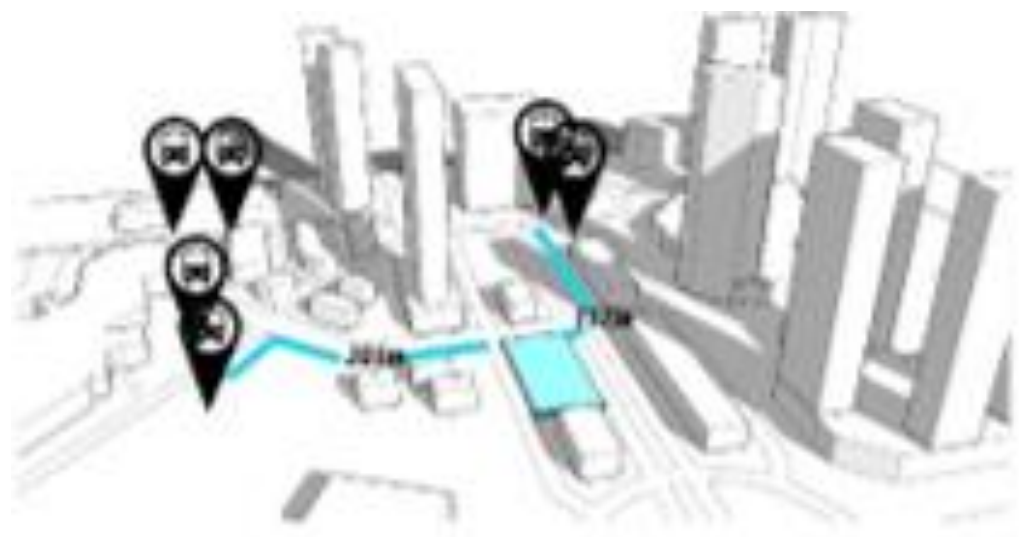

Gambar 3. Lokasi Halte

Sumber: Penulis, 2019

- Jalur Pejalan kaki

Jalur pejalan kaki disesuaikan dengan jarak terdekat antara halte menuju tapak, juga koneksi antara tapak dengan lingkungan sekitar, sehingga pencapaian pejalan kaki menuju tapak tidaklah jauh. Jalur terdekat yang dapat dicapai ke tapak yaitu melalui Jl. Puri Lingkar Dalam.

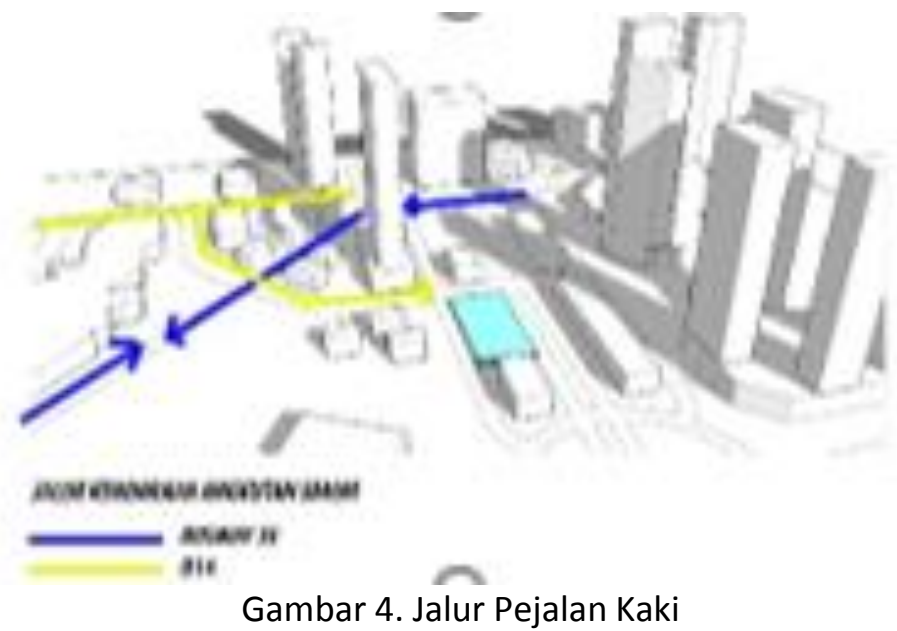

Sumber: Penulis, 2019 
- Jalur Transportasi Umum

Pertimbangan Entrance juga dilihat dari adanya jalur transportasi umum, sehingga tidak terjadi cross antara jalur pejalan kaki dan jalur kendaraan lainnya. Jalur transportasi umum melalui Jl. Puri Lingkar Dalam

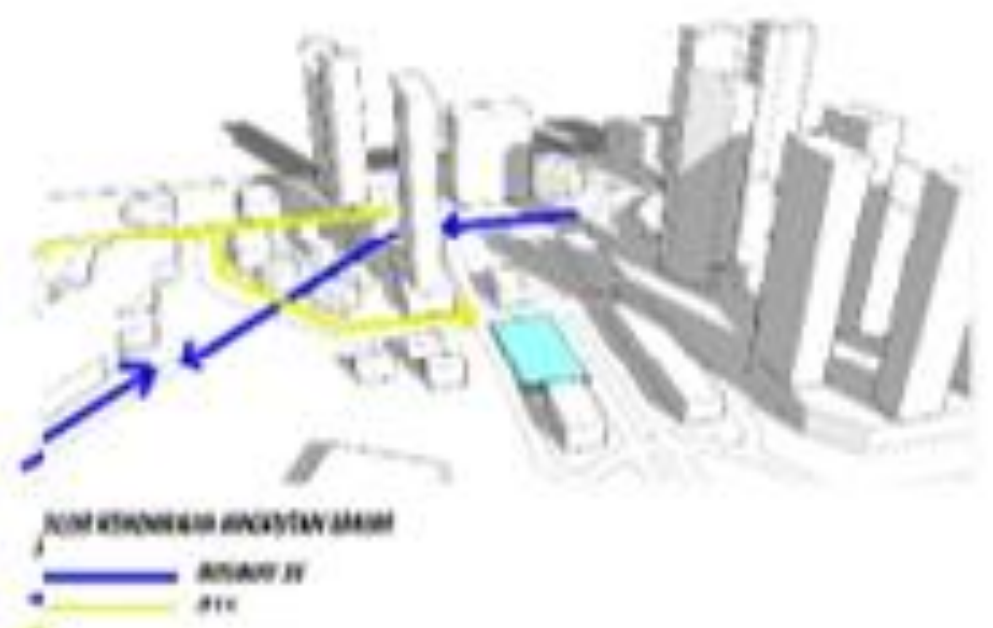

Gambar 5. Jalur Transportasi Umum

Sumber: Penulis, 2019

\section{Massa Bangunan Sekitar}

Dalam mengeksekusi bentuk desain, perlu mengetahui bentuk atau massa bangunan disekitar lingkungan agar menyatu dan terlihat harmonis. Berikut beberapa bangunan di sekitar tapak.

- PX Pavillion

Bentuk pada PX Pavillion ini cenderung persegi panjang, ada sedikit bentukan keluar dan masuk pada bangunan ini. Material yang digunakan didominasi oleh kaca serta ACP atau Allumunium Composite Panel.

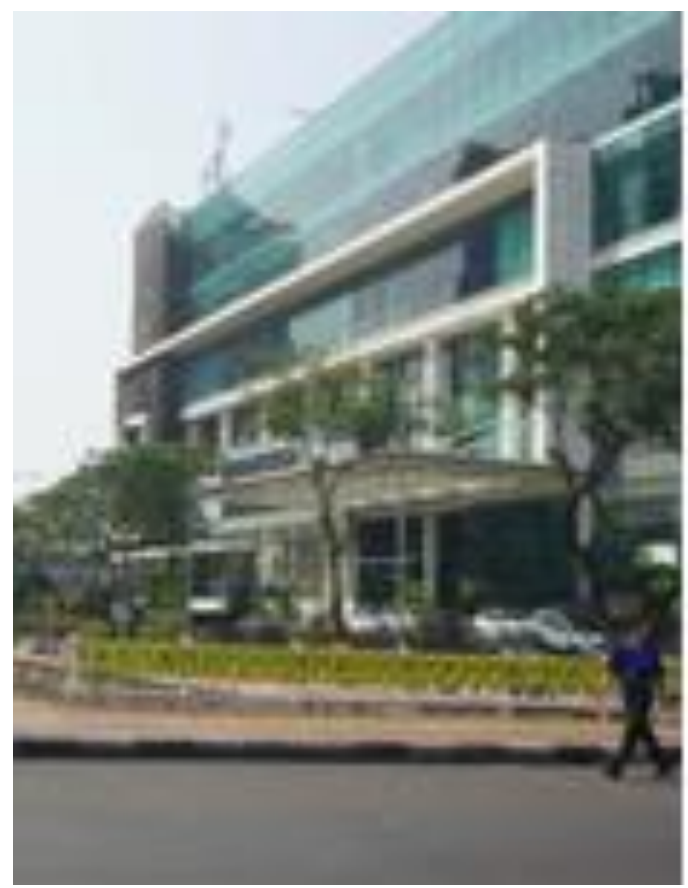

Gambar 6. Bangunan PX Pavillion

Sumber: Penulis, 2019 
- Kantor CNI

Bentuk kantor $\mathrm{CNI}$ ini juga persegi. Penggunaan material pada bangunan ini didominasi juga oleh kaca.

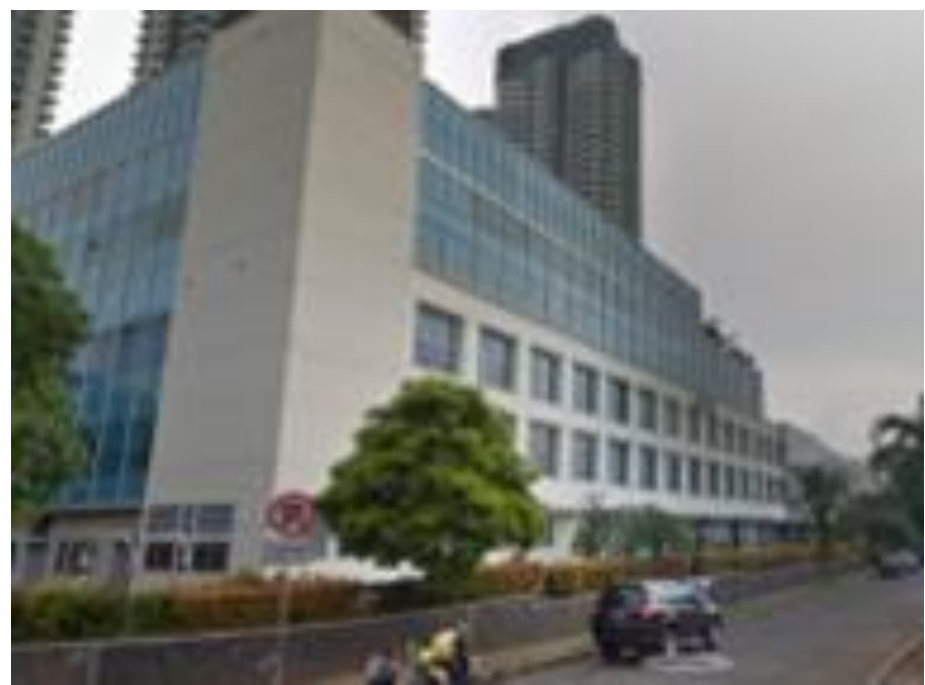

Gambar 7. Bangunan Kantor CNI

Sumber : google maps

- Puri Indah Financial Tower

Bentuk bangunan Puri Indah Financial Tower ini juga persegi. Material pada bangunan ini juga didominasi oleh kaca.

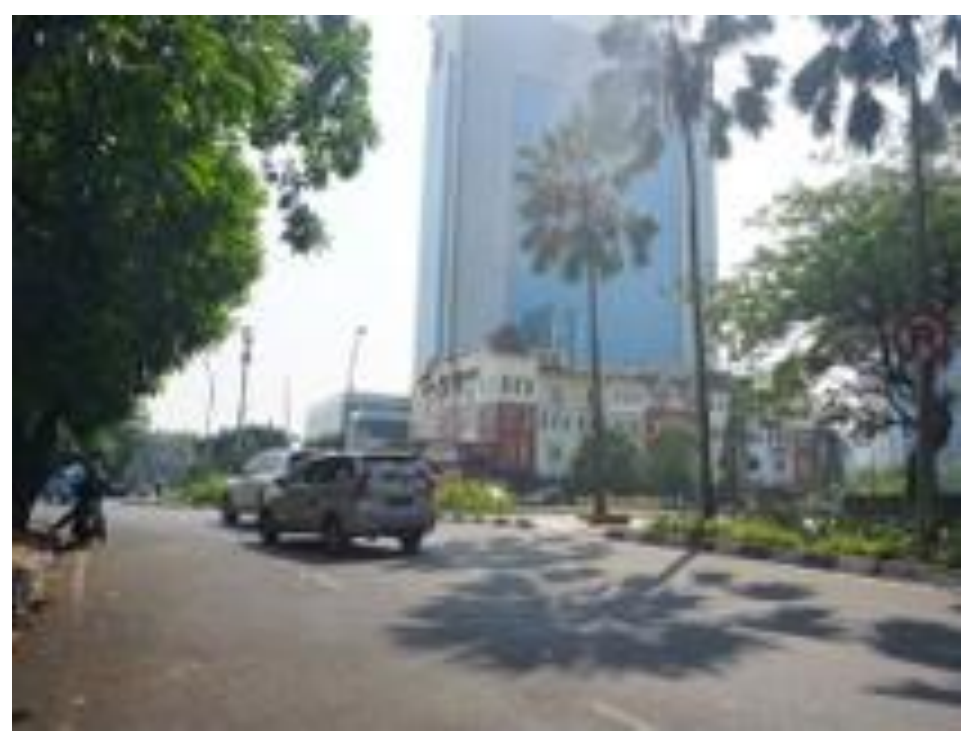

Gambar 8. Bangunan Kantor CNI

Sumber: Penulis, 2019

\section{Massa Bangunan}

Berdasarkan metode simbiosis yaitu menyatukan dua hal yang berbeda, untuk menyesuaikan apa yang terjadi sekarang dan yang akan datang (Kurokawa, 1991). Maka dalam proses gubahan massa, dibentuk sesuai dengan bentuk bangunan lingkungan serta isu yang terjadi pada kawasan Kembangan Selatan yaitu pedagang kaki lima dan mall yang menjadi pemisah antara kalangan menengah keatas dan menengah kebawah. Simbiosis ini menyatukan antara kekosongan dan keberadaan, dimana kekosongan itu diwujudkan dalam sebuah rangka, dan keberadaan dengan bentuk solid. 

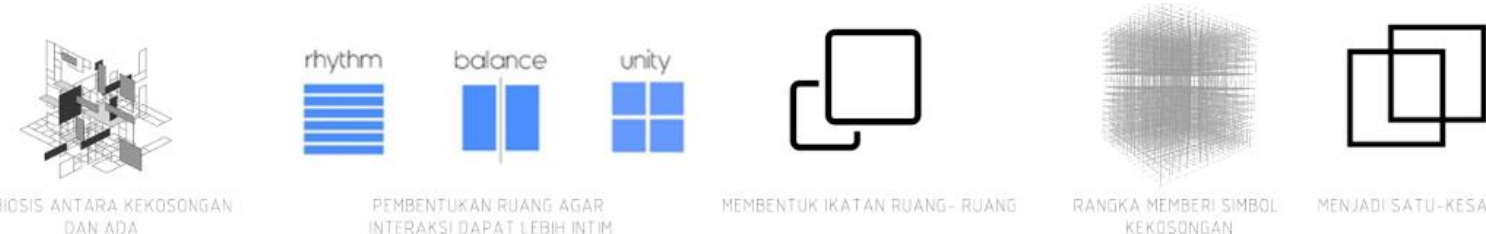

Gambar 9. Konsep Simbiosis

Sumber: Penulis, 2019

Kaitannya teori bentuk mengikuti fungsi dengan simbiosis yaitu, dalam bangunan ini yang berfungsi sebagai wadah komunitas musik, dimana musik itu sendiri memiliki harmonisasi dalam pembentukan nada (Sylado, 1983). Sehingga perlu adanya harmonisasi bentuk massa bangunan sendiri menyesuaikan dengan lingkungan sekitar.
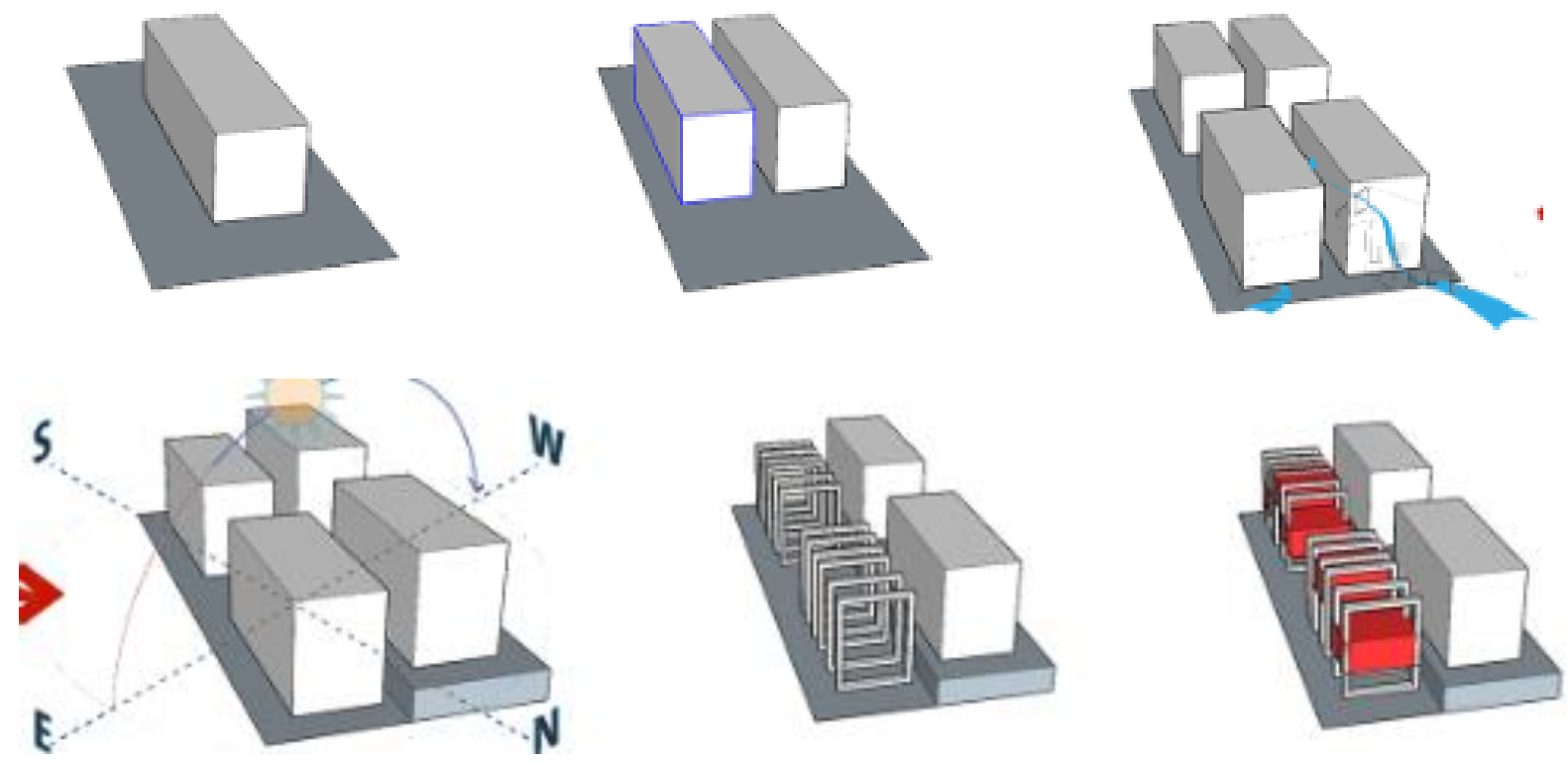

Gambar 10. Proses Gubahan Massa

Sumber: Penulis, 2019

\section{Program Ruang}

Secara general, program ruang yang dibentuk pada penelitian ini dibagi menjadi tiga, yaitu :

Entertain

Solo Performance Space

Group Performance Space

Indoor Music Center

Outdoor Music Center

Recording Studio

Akapela Room

Neighbourhood Space
Komersil

Coffee Shop

Retail Space

Retail Music Instrument
Service

Tempat Penyimpanan Alat Musik

Toilet

R. Pompa

R. Genset

R. Panel

R. GWT

R. STP

R. WTP 


\section{Program}

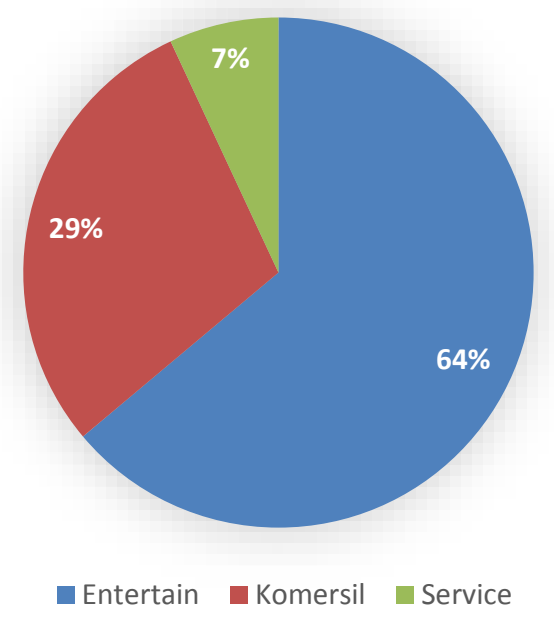

Gambar 11. Diagram Program

Sumber: Penulis, 2019

Hasil dari perancangan ini terbentuk sesuai dengan analisis dan metode yang digunakan. Akses untuk pejalan kaki, yaitu dari Jl. Puri Lingkar Dalam, kemudian untuk akses kendaraan pribadi dari Jl. Puri Molek. Bentuk bangunan mengacu pada analisis bentuk bangunan sekitar, dengan metode yang digunakan yaitu simbiosis dan bentuk mengikuti fungsi. Dimana bangunan sekitar berbentuk persegi, sehingga aplikasi dalam bentuk perancangan ini juga menyesuaikan dengan bentuk lingkungan sekitar. Pada bangunan ini juga menggunakan material baja yang menjadi struktur utama. Dimana baja tersebut diartikan sebagai rangka, yaitu kekosongan. Kemudian bentuk solid menyesuaikan dengan keberadaan sesuai dengan simbiosis yang dilakukan dalam metode yang dibahas sebelumnya.

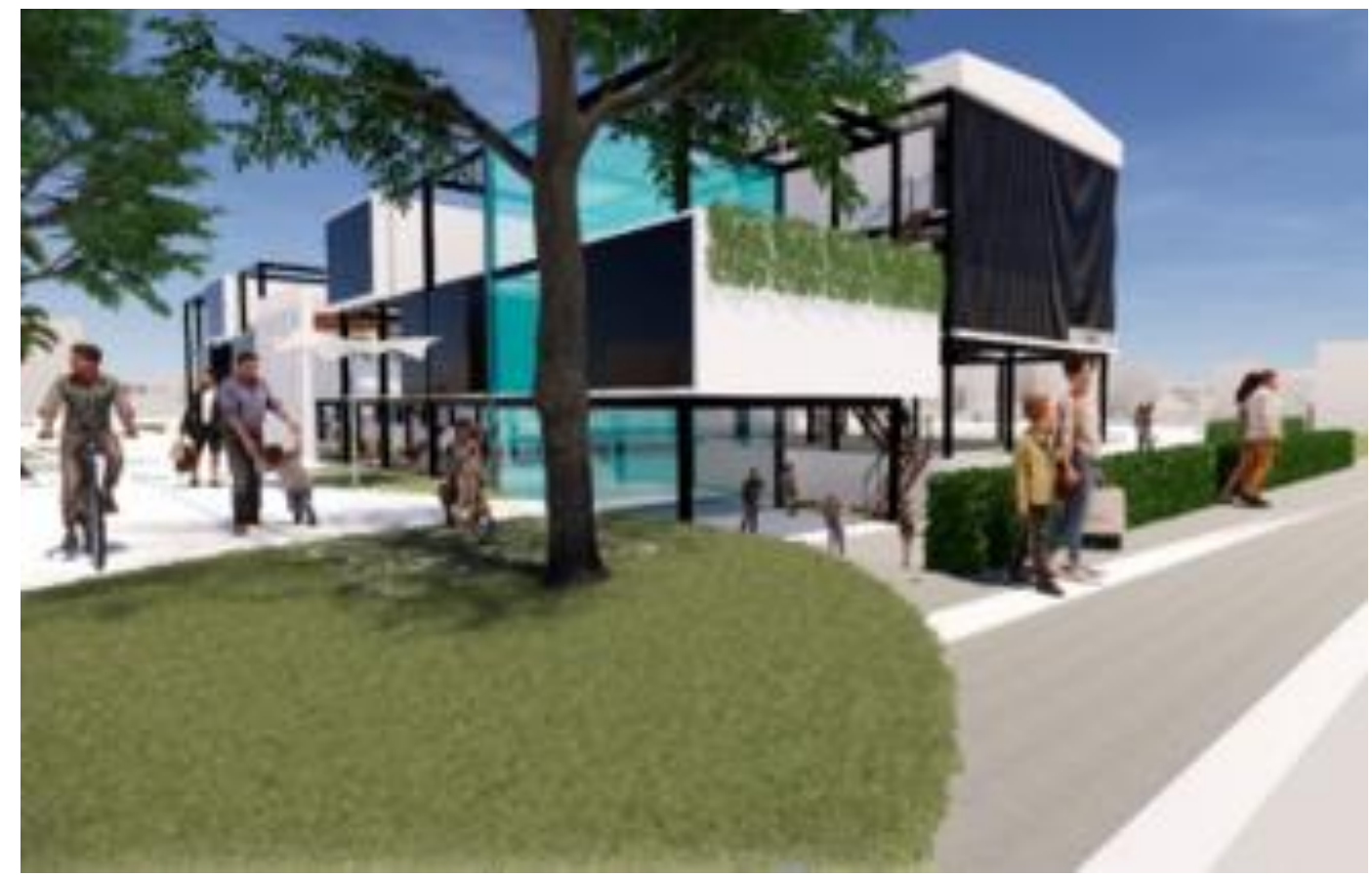

Gambar 12. Perspektif Wadah Komunitas Musik di Kembangan Selatan

Sumber: Penulis, 2019 


\section{KESIMPULAN DAN SARAN \\ Kesimpulan}

Kelurahan Kembangan Selatan memiliki akses yang cukup baik, mulai dari pejalan kaki, angkutan kendaraan umum dan halte. Kemudian yang diperhatikan untuk tapak proyek adalah jalur masuk pejalan kaki dan kendaraan pribadi, agar jalur tersebut tidak terjadi cross atau memotong jalur lain, juga menjaga mobilitas area tapak tersebut agar tidak terjadi kemacetan. Berdasarkan latar belakang kawasan Kembangan Selatan, analisis, serta metode yang digunakan. Maka tugas akhir dengan tema perancangan Open Architecture - architecture for third place, judul perancangan diambil adalah "Wadah Komunitas Musik di Kembangan Selatan" Kemudian dalam penyelesaian bentuk bangunan, menggunakan teori bentuk mengikuti fungsi, dimana fungsi bangunan ini sebagai wadah komunitas musik. Dalam musik, diperlukan harmonisasi dari alunan serta irama nada. Sehingga dari teori bentuk mengikuti fungsi ini, terjadi simbiosis yaitu, keberadaan dan kekosongan. Simbiosis ini mencerminkan bentuk bangunan lingkungan sekitar kawasan Kembangan Selatan dengan bentuk persegi. Karena itu bentuk rancangan bangunan berupa rangka yang mengartikan kekosongan dan bentuk solid yang mengartikan keberadaan. Dengan demikian, penyelesaian rancangan wadah komunitas musik ini dapat sesuai dengan sasaran dan memiliki makna yang mendalam. Dengan adanya wadah komunitas musik ini, masyarakat Kembangan Selatan yang memiliki komunitas musik, dapat menyalurkan hobi mereka, serta menjadi penghubung antara kalangan menengah kebawah dan menengah keatas. Wadah komunitas musik ini juga diharapkan mampu untuk memberi pertumbuhan yang baik bagi lingkungan dan perkotaan.

\section{REFERENSI}

Agyeman, J. (2015). Sharing Cities : A Case for Truly Smart and Sustainable Cities. London: The MIT Press.

Banoe. (2003). Kamus Musik. Yogyakarta: Kanisius.

Frederickson. (2009). Positivity. New York: Crown.

Kurokawa, K. (1991). The Philosophy of Symbiosis. London: Academy Editions.

Oldenburg, R. (1999). The Great Good Place. New York: Marlowe \& Co.

Soemarwono, O. (1994). Ekologi Lingkungan Hidup dan Pembangunan. Bandung: Djambatan. Sylado, R. (1983). Munuju apresiasi musik. Bandung: Angkasa.

Trisno, R., \& Lianto, F. (2019). Relationship Between Function-Form in The Expression of Architectural Creation. Relationship Between Function-Form in The Expression of Architectural Creation.

Wei Z. G. L. (2009). Meeting and greeting: Activities in public outdoor spaces outside highdensity urban residential communities. Journal of Urban Design International. 